\title{
31. Providing electricity from rice husk in rural India
}

\section{Claude Henry}

In 2007, an Indian engineer, Gyanesh Pandey, who had graduated in electrical engineering from Rensselaer Polytechnic Institute (Troy, NY), and who at the time had a good job in Los Angeles, decided to head back to his native Bihar. Bihar is mostly rural and is one of the poorest states in the Indian Federation. More than 80 percent of households there are deprived of access to electricity, a proportion that both reveals and breeds poverty. Those who can afford them use inconvenient and costly kerosene lamps that generate indoor pollution; diesel generators, also polluting and costly, are used to pump water for irrigation and sustain artisanal and commercial activities.

Pandey himself doesn't come from a well-off family, and as a child he suffered from a lack of proper lighting. By 2007, he was determined to try to muster his technical skills to remedy the situation in his home state. After a few unconvincing attempts with solar cells and biofuels, he came upon the idea of using rice husk to generate electricity. He teamed up with a local entrepreneur and with two Indian graduates from Virginia University's Darden School of Business, one of them the current CEO, Manoj Sinha, and Husk Power Systems was started in 2009.

In Bihar, rice is the dominant crop; husk, that is, the envelope of the rice grains, is thus abundant. It is good neither for burning in stoves (because of its very high silica content) nor for returning nutrients to the soil (because of its low nutrient content). However, it can be decomposed by fermentation in a gasifier. Because it had very few uses, 75-80 percent of the 2 million tons obtained each year, as a by-product of the rice crop, was rotting in landfills. The resource is thus plentiful, and its use as a precursor of fuel doesn't harm any other activity.

At Husk Power Systems, small, simple gasifiers are fed with husk. The gas is then burnt to drive a turbine, from which electricity is produced in a standard way. Typically, a $30-40 \mathrm{~kW}$ plant consumes $50 \mathrm{~kg}$ of husk per hour. The components, from which these mini power plants are made, are not tailor-made; they are bought in such conditions that costs are minimized; however, their 
arrangement into specific equipment is innovative, with its quest for simplicity and efficiency in using an unusual fuel.

Typically, the investment cost is about $\$ 1300$ per $\mathrm{kW}$, partially paid for by consumers and partially by modest grants from the Indian federal government, the International Finance Corporation and foundations like the Shell Foundation and the Alstom Foundation. The variable cost is about $\$ 0.15$ per $\mathrm{kWh}$ and is covered by consumers in return for the delivery of enough electricity for one or two low-consumption bulbs and mobile phone recharges; what consumers pay is about half the cost of running a kerosene lamp. Electricity is distributed through local mini networks, that is, simple wiring of a few villages up to $300-500$ households in total. For them, it becomes possible to extend home activities, in particular student work, beyond daylight hours. For artisanal and commercial activities, it represents a less polluting, more convenient and cheaper source of energy, making them more productive. Each local network enables a saving of about $40.000 \mathrm{~L}$ of kerosene and $18.000 \mathrm{~L}$ of diesel per year.

At the "Husk Power University" (more accurately, a "Technical School"), most students are recruited locally. They are trained either as "plant's junior mechanic" - with the perspective of being put in charge of operation and maintenance of a single plant (an eight-week course) - or "senior mechanic" and middle manager for a number of plants, with the ability to face more intricate problems than those dealt with at plant level (a six-month course).

Husk Power Systems is more than a technical innovation, however valuable it is in this respect. It integrates, into the economic life of the communities involved, a local, abundant and underutilized raw resource. It also promotes local talent. And, providing an essential service, it transforms the economic, social and health conditions of the communities it serves.

Within four years, about 80 plants and networks have been set up with cumulative improvements in service and costs. The pace of development is accelerating and inroads have been made into a neighboring state, Uttar Pradesh, as well as in East Africa; there is also interest in Bangladesh. The main lesson of the endeavor is about how to create a system providing an essential service, adapted to the needs of poor people, out of the material and labor resources that are readily available locally. 